\title{
A Study on Turbidity Estimation Using Remote Sensing Techniques
}

\author{
Mustafa Akgun (Corresponding author) \\ Environment Engineering, Ardahan University, Ardahan, Turkey \\ E-mail: mustafaakgun@ardahan.edu.tr \\ Yalcin Kemal Bayhan \\ Environment Engineering, Atatürk University, Erzurum, Turkey \\ E-mail: ybayhan@atauni.edu.tr \\ Necla Barlik \\ Environment Engineering, Ardahan University, Ardahan, Turkey \\ E-mail: neclabarlik@ardahan.edu.tr
}

\begin{abstract}
In this study, the turbidity level of Karagöl, a national park area within the boundaries of Şavşat district of Artvin province, was mapped with Göktürk-2 satellite data. Turbidity is an important parameter of water quality. The traditional measurement of turbidity levels of lakes is relatively costly, requiring time-consuming and on-site sampling. Therefore, detection of turbidity is important for the protection and management of water resources. For this purpose, the turbidity levels of the samples taken from the predetermined points were measured on August 18, 2017 and July 11, 2018 and an empirical model was developed with the data obtained from these field studies. This model was developed from the spectral reflectance values of the blue green and red bands of the image obtained on the same date from the Göktürk-2 satellite. This model developed was applied to Göktürk-2 satellite images and the turbidity maps of the lake were extracted. In addition, the model was used to estimate the turbidity value of the lake and gave reasonable results. The regression coefficient $\left(\mathrm{R}^{2}\right)$ of the developed model was found to be 0.80 .
\end{abstract}

Keywords: Remote sensing, Turbidity, Göktürk-2, the Lake Karagöl

DOI: $10.7176 / J S T R / 5-3-18$

\section{Uzaktan Algılama Tekniklerini Kullanarak Bulanıklık Tahmini Üzerine Bir Çalışma}

\section{Özet}

Bu çalışmada, Artvin ili Şavşat ilçesi sınırları içinde bulunan bir milli park alanı olan Karagöl’ün bulanıklık düzeyinin Göktürk-2 uydusu verileri ile haritalanması yapılmıştır. Bulanıklık önemli bir su kalitesi parametresidir. Göllerin bulanıklık seviyelerinin geleneksel ölçümü zaman alıcı ve yerinde örneklemeyi gerektiren nispeten maliyetlidir. Bu sebeple bulanıklığın tespiti su kaynaklarının korunması ve yönetilmesi açısından önem taşımaktadır. Bu amaçla 18 Ağustos 2017 ve 11 Temmuz 2018 tarihlerinde olmak üzere önceden belirlenen noktalardan alınan örneklerin bulanıklık düzeyleri ölçülmüş ve bu saha çalışmalarından elde edilen verilerle amprik bir model türetilmiştir. Bu model, Göktürk-2 uydusundan aynı tarihte elde edilen görüntünün mavi, yeşil ve kırmızı bantlarının spektral yansıma değerlerinden geliştirilmiştir. Geliştirilen bu model gene aynı tarihte çekilen Göktürk-2 uydu görüntülerine uygulanmış ve gölün bulanıklık haritaları çıkarılmıştır. Ayrıca geliştirilen model gölün bulanıklık değerini tahmin etmek için kullanılmış ve Kabul edilebilir sonuçlar vermiştir. Geliştirilen modelin regresyon katsayısı $\left(\mathrm{R}^{2}\right)$ yüksek bir değer olan 0.80 olarak bulunmuştur.

Anahtar sözcükler: Uzaktan algılama, Bulanıklık, Göktürk-2, Karagöl 


\section{Giriş}

Su kalitesi parametrelerinin uzaktan algılama teknolojisi ile izlenmesine yönelik çalışmaların (Toming et al., 2016; Zuccari Fernandes Braga, Setzer, \& Drude de Lacerda, 1993), son günlerde popülerlik kazandığı söylenebilir. Özellikle son zamanlarda uydu görüntülerine geçmiş yıllara oranla nispeten kolay ulaşılabilmesi, uzaktan algılama çalışmalarına hız kazandırmıştır(M. Özerdem, Acar, \& Ekinci, 2017; M. S. Özerdem \& Acar, 2017). Bu noktada, uzaktan algılama teknolojisi, çevre kirliliğine yönelik analizlerin hızlı, etkili ve kolay bir şekilde yapılabilmesine imkân sunmaktadır (Dlamini, Nhapi, Gumindoga, Nhiwatiwa, \& Dube, 2016; Watanabe et al., 2015). Çevre kirliliğinin su kalitesi boyutuna odaklanan çalışmalar incelendiğinde (Brezonik, Olmanson, Finlay, \& Bauer, 2015; Dogliotti, Ruddick, Nechad, Doxaran, \& Knaeps, 2015; Hasmadi \& Norsaliza, 2010; Hellweger, Miller, \& Oshodi, 2007; Kutser, Pierson, Kallio, Reinart, \& Sobek, 2005), uzaktan algılama teknolojisi yardımıyla klorofil ve bulanıklık değerleri belirlenebilmekte ve böylece su kalitesi izleme çalışmaları uzaktan yapılabilmektedir. Uydudan alınan görüntüler üzerinde matematiksel modeller geliştirilerek klorofil değeri tahmin edilebilmekte (Abdelmalik, 2016; Hartnett \& Nash, 2015; Strömbeck \& Pierson, 2001) ve arazi çalışmasına ihtiyaç duyulmadan su kalitesine ilişkin somut bulgular elde edilebilmektedir.

Uzaktan algılama; objelere fiziksel temasta bulunmadan herhangi bir uzaklıktan yapılan ölçme, nesneler hakkında bilgi edinme bilim ve sanatı şeklinde tanımlanmaktadır (Sönmez \& Sarı, 2002). Su kalitesini uzaktan algılamayla belirlemeye yönelik çalışmalar Landsat uydusunun firlatılmasıyla başlamış ve günümüzde de devam etmektedir (Gholizadeh, Melesse, \& Reddi, 2016; Lathrop \& Lillesand, 1986; Lillesand, Johnson, \& Deuell, 1983). Su kalitesi parametrelerini belirlemeye yönelik çalışmalarda, yeşil, kırmızı ve kızılötesi bantlar tekil olarak ve bu bantların kombinasyonları olarak kullanılmıştır (Hasmadi \& Norsaliza, 2010; Somvanshi.S, Kunwar.P, Singh.N.B, Shukla.S.P, \& Pathak.V, 2012). Uzaktan algıma yöntemi ile mevcut durumun ortaya konulabilmesinin yanı sıra geçmiş verilerin işlenmesi ile sürecin işleyişini ve ilerleyişini belirlemek de mümkün olabilmektedir.

Kirleticiler su kaynaklarına bir veya daha fazla noktadan karışabilmekte ve karıştıkları su kaynağının kimyasal ve fiziksel özelliklerini değiştirmektedirler. Su kalitesinin bozulmasında kirleticilerin yanı sıra sıcaklık, yağış, su kaynağının hidrolik özellikleri ve diğer hidrolik süreçler de etkili olabilmektedir (Barut et al., 2015). Uzaktan algılama teknolojileri kullanılarak bir model oluşturulması ve bu modele göre su kaynaklarının izlenmesi ile ilgili birçok çalışma yapılmıştır (Mouw et al., 2015; Palmer et al., 2015; Zhou \& Zhao, 2011).

Bu çalışma için Artvin ili Şavşat ilçesi sınırları içerisinde bulunan Sahara Milli Parkı'nda ki Karagöl seçilmiş̧ir. Göldeki bulanıklık düzeyleri ile uydu görüntülerinden türetilen kızılötesi, kırmızı ve mavi bantlar ve bunların kombinasyonları arasındaki korelasyonlar araştırılmıştır.

\section{Materyal ve Metot}

\section{1. Çalışma alanı}

Artvin ili Şavşat ilçesi sınırları içinde bulunan çalışma alanı $\left(41^{\circ} 18^{\prime} 0^{\prime \prime} \mathrm{N}, 42^{\circ} 29^{\prime} 0^{\prime \prime}\right.$ E) bir milli park alanıdır. Karagöl'ün alanı yaklaşık olarak 5 hektar olup çalışma alanı Şekil 1'de gösterilmiştir.

İlki 18 Ağustos 2017 ve ikincisi 11 Temmuz 2018 tarihlerinde olmak üzere önceden belirlenen noktalardan alınan örneklerde bulanıklık düzeyleri ölçülmüştür.

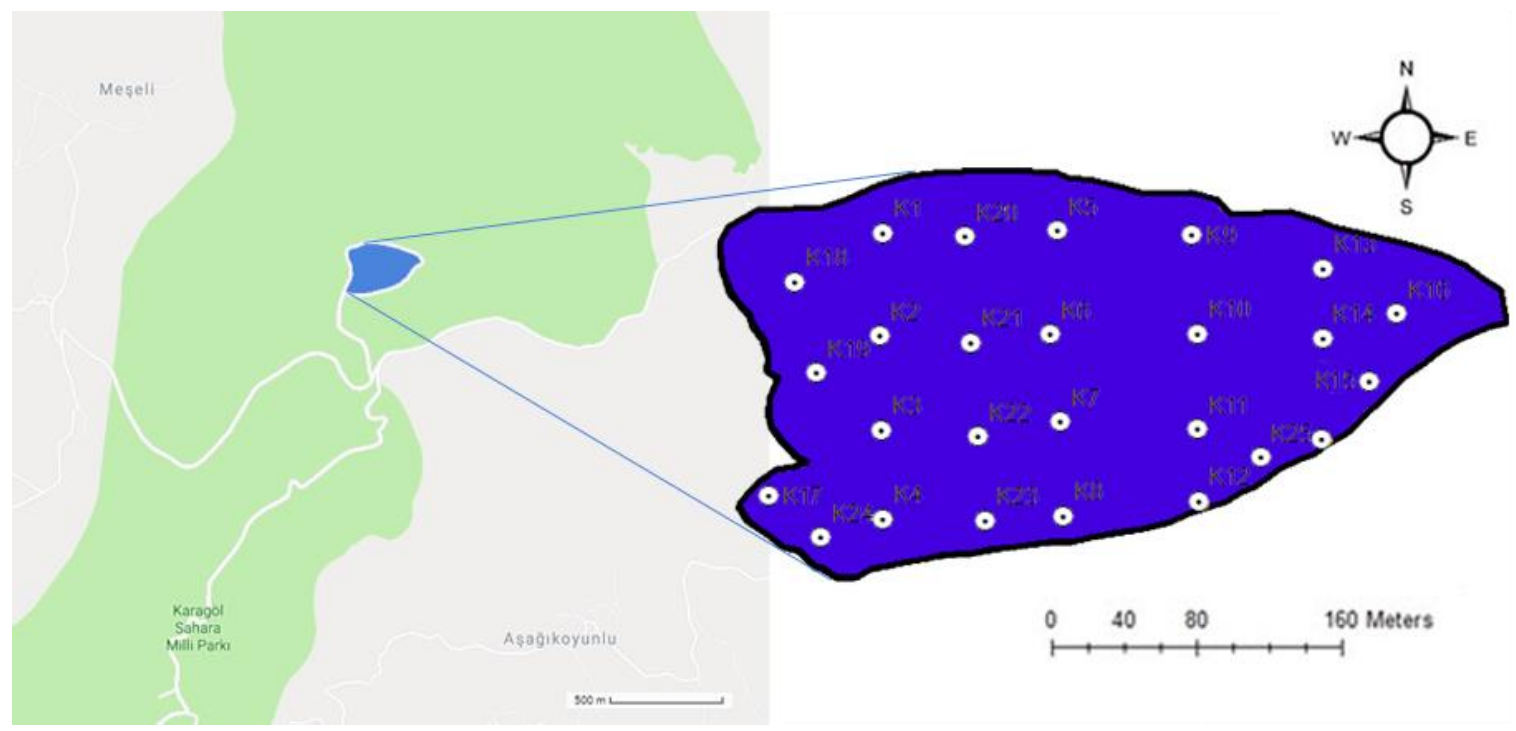

Şekil 1. Karagöl'ün konumu 


\subsection{Veri toplama}

2.2.1 Uydu görüntüsü verilerinin toplanmas1

Göktürk-2 uydusu 18 Aralık 2012 tarihinde firlatılmıştır. $409 \mathrm{~kg}$ ağırlığındaki uydu $2.5 \mathrm{~m}$ siyah beyaz, $5 \mathrm{~m}$ renkli çözünürlüğe sahiptir. Tekrar ziyaret zamanı ortalama 2.5 gündür. Göktürk-2 uydusunun 5 spektral bandı vardır. Bunlar mavi $(0.422-0.512 \mu \mathrm{m})$, yeşil $(0.5-0.584 \mu \mathrm{m})$, kırmızı $(0.596-0.750 \mu \mathrm{m})$, yakın kızı̈losesi $(0.762-0.894 \mu \mathrm{m})$ ve orta kızılötesi (0.8-1.7 $\mu \mathrm{m}$ ) bantlardır (Atak, Erdoğan, \& Yılmaz, 2015). Uydu görüntüleri, 18 Ağustos 2017 ve 11 Temmuz 2018 tarihlerinde Göktürk-2 uydusunun işletmesini yapan Türk Hava Kuvvetleri Keşif ve Uydu Komutanlı̆̆ tarafindan sağlandı.

\subsubsection{Arazi verilerinin toplanmas1}

$\mathrm{Bu}$ araştırmanın çalışma alanı olarak belirlenen Karagöl'den iki farklı tarihte numune alınması planlanmıştır. $\mathrm{Bu}$ plan çerçevesinde; 18 Ağustos 2017 tarihinde ve 11 Temmuz 2018 tarihinde 26 farklı noktadan numune alınmıştır. Böylece çalışmada bulanıklık değerine ilişkin veriler toplam 52 noktadan elde edilmiştir. Ancak bu noktalardan elde edilen verilerden sadece 42 tanesinden sonuç alınabilmiştir. Bulanıklık analizi için numuneler portatif turbüdimetre ile arazide ölçülmüştür. Elde edilen sonuçlar aynı tarihte alınan uydu görüntülerinin işlenmesinde kullanılarak gölün bulanıklık haritaları hazırlanmıştır. Tablo 1 de Karagöl gölünden alınan su numunelerinin koordinatlar1 gösterilmektedir.

Tablo 1. Karagöl gölünden alınan su numunelerinin koordinatları

\begin{tabular}{|c|c|c|}
\hline \multirow{2}{*}{ İstasyon } & \multicolumn{2}{|c|}{ Koordinatlar } \\
\hline & Enlem & Boylam \\
\hline 1 & $411831.1623 \mathrm{~N}$ & $422858.6835 \mathrm{E}$ \\
\hline 2 & $411828.6527 \mathrm{~N}$ & $422859.7407 \mathrm{E}$ \\
\hline 3 & $411828.0851 \mathrm{~N}$ & $422859.7276 \mathrm{E}$ \\
\hline 4 & $411826.8015 \mathrm{~N}$ & $422859.3876 \mathrm{E}$ \\
\hline 5 & $411831.2460 \mathrm{~N}$ & $42292.1934 \mathrm{E}$ \\
\hline 6 & $411829.6001 \mathrm{~N}$ & $42292.5153 \mathrm{E}$ \\
\hline 7 & $411828.1087 \mathrm{~N}$ & $42291.0362 \mathrm{E}$ \\
\hline 8 & $411826.8652 \mathrm{~N}$ & $42291.9501 \mathrm{E}$ \\
\hline 9 & $411831.5507 \mathrm{~N}$ & $42293.6074 \mathrm{E}$ \\
\hline 10 & $411829.5607 \mathrm{~N}$ & $42295.2201 \mathrm{E}$ \\
\hline 11 & $411828.1656 \mathrm{~N}$ & $42294.4874 \mathrm{E}$ \\
\hline 12 & $411827.1905 \mathrm{~N}$ & $42294.0327 \mathrm{E}$ \\
\hline 13 & $411830.2678 \mathrm{~N}$ & $42296.3503 \mathrm{E}$ \\
\hline 14 & $411829.0866 \mathrm{~N}$ & $42296.0179 \mathrm{E}$ \\
\hline 15 & $411827.8035 \mathrm{~N}$ & $42295.6733 \mathrm{E}$ \\
\hline 16 & $411829.9038 \mathrm{~N}$ & $42297.3993 \mathrm{E}$ \\
\hline 17 & $411827.2605 \mathrm{~N}$ & $422857.8358 \mathrm{E}$ \\
\hline 18 & $411830.4878 \mathrm{~N}$ & $422858.1986 \mathrm{E}$ \\
\hline 19 & $411828.5340 \mathrm{~N}$ & $422858.9280 \mathrm{E}$ \\
\hline 20 & $411830.7174 \mathrm{~N}$ & $42290.2669 \mathrm{E}$ \\
\hline 21 & $411828.3750 \mathrm{~N}$ & $42290.8895 \mathrm{E}$ \\
\hline 22 & $411827.6898 \mathrm{~N}$ & $42290.0094 \mathrm{E}$ \\
\hline 23 & $411826.9226 \mathrm{~N}$ & $42290.2836 \mathrm{E}$ \\
\hline 24 & $411826.4870 \mathrm{~N}$ & $422858.4886 \mathrm{E}$ \\
\hline 25 & $411827.3214 \mathrm{~N}$ & $42295.3031 \mathrm{E}$ \\
\hline 26 & $411828.0311 \mathrm{~N}$ & $42296.4416 \mathrm{E}$ \\
\hline
\end{tabular}

$162 \mid \mathrm{P}$ a g e 


\subsection{Veri Analizi}

\subsubsection{Görüntü İsleme}

Görüntülere atmosferik ve radyometrik düzeltme işlemleri, uydunun işletmesini yapan Türk Hava Kuvvetleri Keşif ve Uydu Komutanlığı tarafından yapıldı. Görüntülere geometrik düzeltme işlemi ise ERDAS Imagine yazılımı 2016 versiyonu ile yapıldı. Geometrik düzeltme işlemi UTM koordinat sistemine göre referanslandırıldılar (WGS84, zone 38). Geometrik düzeltme işlemi 15 adet yer kontrol noktasına göre yapıldı ve RMS hataları 1 pikselden daha az olarak elde edildi. Uydu görüntülerindeki ilgilenilen alanın (AOI) çıkarılması için ERDAS Imagine yazılımı, 2016 sürümü kullanıldı. AOI'ler, yer verilerinden ölçülen verilerle ilişki geliştirmek için Göktürk-2'den elde edilen ham görüntüdeki piksel değerlerinin bulunduğu yerlerdir.

\subsection{2 İstatistiksel Analiz}

$\mathrm{Su}$ ampirik model yaklaşımı olarak bilinen, reflektans değerlerine dayanan model ile konsantrasyon belirlenebilmektedir (Hasmadi \& Norsaliza, 2010). Bulanıklık değeri (bağımlı değişkenler) ve Göktürk-2 uydu görüntüsünün kırmızı, yeşil ve mavi bantların piksel değerlerinden ve bu bantların oranlarından elde edilen değerler (bağımsız değişkenler) arasındaki ilişkiyi araştırmak için çoklu doğrusal regresyon kullanılmıştır. Analiz sırasında yüzde 95 güven seviyesi dikkate alınmıştır. İstatistiksel analiz için IBM SPSS Statistics 20 yazılımı kullanılmıştır.

Işınım değerine sahip olan geometrik olarak düzeltilmiş görüntülerde, farklı oranlardaki ışınım değerlerinin etkisini azaltmak için bant oranlaması kullanılmıştır. Oranlama, aynı biyofiziksel olguya ait iki farklı yansıma değerleri arasında bir ilişki olduğunda yetersiz veriyi geliştirmek veya etkin hale getirmek için etkilidir (Somvanshi.S, Kunwar.P, Singh.N.B, Shukla.S.P, \& Pathak.V, 2012). Su kütlelerinin incelenmesi için en yararlı bantlar kırmızı, yeşil ve yakın kızılötesidir (Somvanshi.S et al., 2012). Bu çalışmada kullanılan bant oranları R-B ve R -G'dir. Bu oranlar Erdas Imagine yazılımı 2016 sürümünün modülü kullanılarak yapıldı.

\section{Bulgular ve Tartışma}

\subsection{Bulanıklık değerlerine yönelik bulgular}

Tablo 2 de Karagöl gölünden 18 Ağustos 2017 tarihinde alınan su numunelerinin bulanıklık değerlerinin 1.05 NTU ile 1.41 NTU arasında olduğu, 11 Temmuz 2018 tarihinde alınan su numunelerinin bulanıklık değerlerinin 0.78 NTU ile 1 NTU arasında olduğu görülmektedir.

\subsection{Bulanıklık verisinin haritalanması}

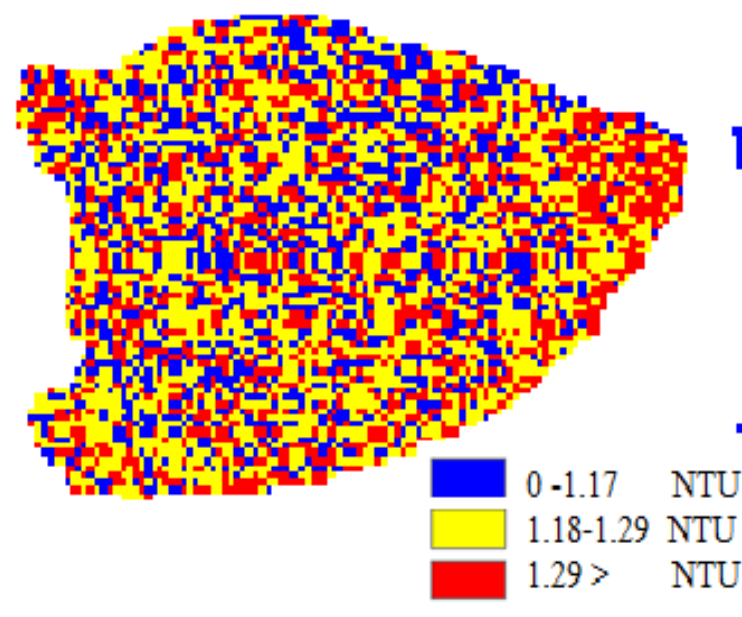

(a)

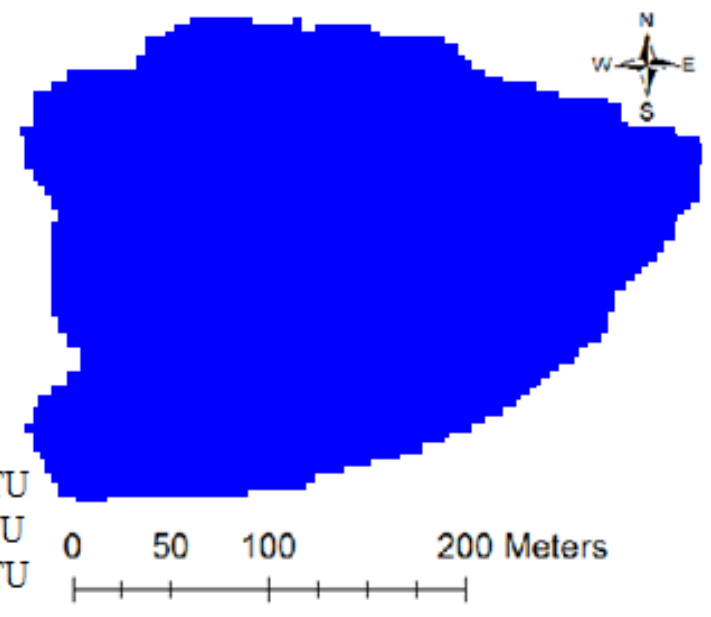

(b)

Şekil 2. Karagöl’ün 18 Ağustos 2017 tarihli bulanıklık derecesini gösteren haritası (a), Karagöl'ün 11 Temmuz 2018 tarihli bulanıklık derecesini gösteren haritası (b)

Genel olarak, bulanıklık sudaki askıdaki katı maddelerden kaynaklanmaktadır. Şekil 2a, Karagöl'ün 18 Ağustos 2017 tarihli ve Şekil 2b, Karagöl'ün 11 Temmuz 2018 tarihli tematik bir bulanıklık derecesi haritasını 
göstermektedir. $\mathrm{Bu}$ haritaların hazırlanmasında kırmızı, yeşil ve mavi bantların piksel değerlerinin oranları kullanılmıştır. Bulanıklık haritaları oluşturulurken bant oranları kullanılmasının nedeni; topoğrafik düzensizlikten kaynaklanan ve değişik aydınlanmaya neden olan gölge faktörünün etkisinin azaltılabilmesi ve aynı biyofiziksel olguya ait iki farklı yansıma değerleri arasında bir ilişki olduğunda yetersiz veriyi geliştirmek veya etkin hale getirmek içindir. Bu oranlar doğrultusunda elde edilen bulanıklık değerleri için hazırlanan haritalarda gölün bulanıklık seviyesi üç sınıfa ayrılmıştır. Birinci sınıf (<1.17 NTU) kırmızı olarak, ikinci sınıf $(1.18-1.29$ NTU) sarı olarak ve üçüncü sınıf (>1.29 NTU) mavi olarak gösterilmiştir.

Tablo 2. 18 Ağustos 2017 ve 11 Temmuz 2018 tarihlerinde Karagöl gölünden alınan su numunelerinin bulanıklık değerleri

\begin{tabular}{|c|c|c|}
\hline İstasyon & 11 Temmuz 2018 & 18 Ağustos 2017 \\
\hline 1 & 0.87 & 1.17 \\
\hline 2 & 0.78 & 1.32 \\
\hline 3 & 0.97 & 1.25 \\
\hline 4 & 0.93 & 1.18 \\
\hline 5 & 0.89 & 1.29 \\
\hline 6 & 0.97 & 1.27 \\
\hline 7 & 0.88 & $-*$ \\
\hline 8 & 0.97 & 1.15 \\
\hline 9 & 0.85 & 1.10 \\
\hline 10 & 0.82 & 1.09 \\
\hline 11 & 0.99 & $-*$ \\
\hline 12 & 0.95 & 1.09 \\
\hline 13 & 0.84 & 1.05 \\
\hline 14 & 0.92 & $-*$ \\
\hline 15 & 0.94 & 1.12 \\
\hline 16 & 0.93 & 1.22 \\
\hline 17 & 0.89 & 1.23 \\
\hline 18 & 1.00 & 1.41 \\
\hline 19 & 0.88 & 1.16 \\
\hline 20 & 0.83 & $-*$ \\
\hline 21 & 0.82 & $-*$ \\
\hline 22 & 0.95 & $-*$ \\
\hline 23 & 0.96 & $-*$ \\
\hline 24 & 0.85 & $-*$ \\
\hline 25 & 0.87 & -* \\
\hline 26 & 0.8 & $-*$ \\
\hline
\end{tabular}

* Bulanıklık değeri okunamadığından hesaplamaya dâhil edilmemiştir. 


\subsection{Uydu verilerinden tahmini bulanıklık değeri için regresyon modelinin geliştirilmesi}

$\mathrm{Bu}$ çalışmada görüntü analiziyle bulanıklık miktarının belirlenebilmesine yönelik bir model geliştirilmesi amaçlanmıştır. Bu amaç doğrultusunda, hangi bantlar ile bulanıklık değeri arasında istatistiksel olarak anlamlı bir ilişki olduğu sorgulanmıştır. Bu noktada, bant oranlarının kullanılması ile bir model geliştirilmesi ve bu modele bağlı olarak tahminleme yapılması yöntemi kullanılmıştır. R-B ve R-G oranları ile bulanıklık değeri arasında istatistiksel olarak anlamlı ve pozitif yönlü bir ilişkisi olduğu anlaşılmıştır. Tahmin edilen bulanıklık değeri, öngörülen model kullanılarak, ölçülen bulanıklık değerine göre kıyaslanmıştır. Bulanıklık değerini tahmin etmek için geliştirilen modelde, bağımlı değişken ile en yüksek düzeltilmiş regresyon katsayısı $\left(\mathrm{R}^{2}=0,80\right)$ değerine sahip olan bağımsız değişkenlerin kombinasyonu seçilmiştir.

Tablo 3. Bulanıklık Regresyon Denklemi ve Katsayı Değerleri

\begin{tabular}{ccc}
\hline & $Y$ & Bulanıklık (NTU) \\
\cline { 2 - 3 } & \multicolumn{1}{c}{$a$} & 0.657 \\
\cline { 2 - 3 } & $b$ & 0.002 \\
\cline { 2 - 3 } & $c$ & 0.004 \\
\hline$X_{1}$ & $\mathrm{R}-\mathrm{B}$ \\
\hline$X_{2}$ & $\mathrm{R}-\mathrm{G}$ \\
\hline
\end{tabular}

Tablo 3'de bulanıklık tahmini için geliştirilen eşitlik ve bu eşitliğin parametreleri verilmiştir. Bu parametrelerden; $Y$ bulanıklık değerini (NTU), $a, b$ ve $c$ katsayıları, $X_{1}$ değeri R-B değerini ve $X_{2}$ değeri R-G değerini ifade etmektedir.

Şekil 3 ölçülen bulanıklık değerine karşılık tahmin edilen bulanıklık değerinin grafiğini göstermektedir.

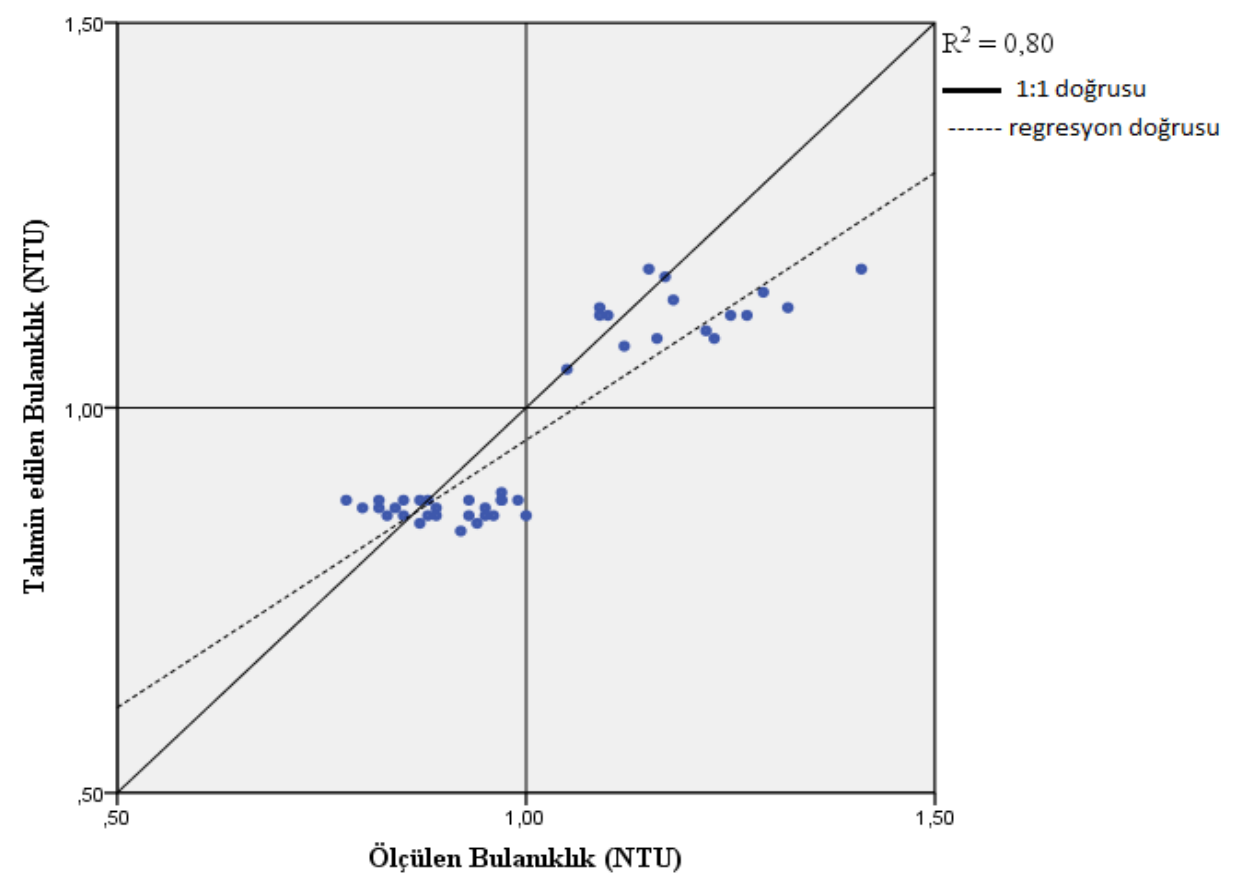

Şekil 3. Ölçülen bulanıklık değerine karşılık tahmin edilen bulanıklık değeri

\section{Sonuç}

Bu çalışma, Karagöl'deki bulanıklık değeri ve Göktürk-2 uydusunun görünür bantları arasında geliştirilen Çoklu Doğrusal Regresyon Denklem Modelinde istatistiksel olarak anlamlı bir ilişki olduğunu göstermiştir. Göktürk-2 uydusunun yansıma değerleri Karagöl'ün bulanıklık değerinin belirlenmesi için başarıyla kullanılabilir. 
Göldeki bulanıklık değerleri istasyon bazında karşılaştırıldığında, 2018 yılında gölün bulanıklık değeri bir önceki yıla oranla azaldığı gözlemlenmiştir. Genel bir modelin geliştirilmesi için yılın farklı zamanlarında ek çalışmalara ihtiyaç duyulmaktadır. Ancak sonbahar ve kış aylarında havanın sisli olması, kış aylarında gölün etrafının karla kaplı olmasından dolayı yansıma değerlerinin etkilenmesi ve kışın göl yüzeyinin donması yılın geneline yayılan bir çalışma yapılmasını ve model geliştirilmesini zorlaştırmaktadır. Yöntemin; tekrarlanan uzaktan algılanan veriler ile yüzey suyu kalitesini tahmin etmeye yönelik bir potansiyele sahip olduğu ve bu amaç için iyi bir alternatif oluşturduğu söylenebilir.

Sonraki çalışmalarımızda makine öğrenmesi yöntemleri kullanarak bulanıklık tahminlemesi gerçekleştirilecektir.

\section{Kaynaklar}

Abdelmalik, K. W. (2016) 'Role of statistical remote sensing for Inland water quality parameters prediction', The Egyptian Journal of Remote Sensing and Space Science. National Authority for Remote Sensing and Space Sciences. doi: 10.1016/j.ejrs.2016.12.002.

Atak, V. O., Erdoğan, M. and Yılmaz, A. (2015) ‘Göktürk-2 Uydu Görüntü Testleri’, Harita Dergisi, pp. 1833.

Barut, I. et al. (2015) 'Determination by Landsat Satellite Imagery to Local Scales in Land and Pollution Monitoring: a Case of Buyuk Melen Watershed (Turkey)', Journal of Sustainable Development of Energy, Water and Environment Systems, 3(4), pp. 389-404. doi: 10.13044/j.sdewes.2015.03.0029.

Brezonik, P. L. et al. (2015) 'Factors affecting the measurement of CDOM by remote sensing of optically complex inland waters', Remote Sensing of Environment. Elsevier Inc., 157, pp. 199-215. doi: 10.1016/j.rse.2014.04.033

Dlamini, S. et al. (2016) 'Assessing the feasibility of integrating remote sensing and in-situ measurements in monitoring water quality status of Lake Chivero, Zimbabwe', Physics and Chemistry of the Earth. Elsevier Ltd, 93, pp. 2-11. doi: 10.1016/j.pce.2016.04.004.

Dogliotti, A. I. et al. (2015) 'A single algorithm to retrieve turbidity from remotely-sensed data in all coastal and estuarine waters', Remote Sensing of Environment. Elsevier B.V., 156, pp. 157-168. doi: 10.1016/j.rse.2014.09.020

Gholizadeh, M., Melesse, A. and Reddi, L. (2016) 'A Comprehensive Review on Water Quality Parameters Estimation Using Remote Sensing Techniques', Sensors, 16(8), p. 1298. doi: 10.3390/s16081298.

Hartnett, M. and Nash, S. (2015) 'An integrated measurement and modeling methodology for estuarine water quality management', Water Science and Engineering, 8(1), pp. 9-19. doi: 10.1016/j.wse.2014.10.001.

Hasmadi, I. M. and Norsaliza, U. (2010) 'Analysis of SPOT- 5 Data for Mapping Turbidity Level of River Klang', Water, 1(2), pp. 14-18.

Hellweger, F. L., Miller, W. and Oshodi, K. S. (2007) 'Mapping turbidity in the Charles River, Boston using a high-resolution satellite', Environmental Monitoring and Assessment, 132(1-3), pp. 311-320. doi: 10.1007/s10661-006-9535-8.

Kutser, T. et al. (2005) 'Mapping lake CDOM by satellite remote sensing', Remote Sensing of Environment, 94(4), pp. 535-540. doi: 10.1016/j.rse.2004.11.009.

Lathrop, R. G. and Lillesand, T. M. (1986) 'Use of thematic mapper data to assess water quality in Green Bay and Central Lake Michigan', Photogrammetric Engineering and Remote Sensing, 52(5), pp. 671-680.

Lillesand, T. M., Johnson, W. L. and Deuell, R. L. (1983) 'Use of landsat data to predict the trophic state of Minnesota lakes', Photogrammetric Engineering and Remote Sensing, 49(2), pp. 219-229. Available at: http://eserv.asprs.org/PERS/1983journal/feb/1983_feb_219-229.pdf.

166 | P a g e

www.iiste.org 
Mouw, C. B. et al. (2015) 'Aquatic color radiometry remote sensing of coastal and inland waters: Challenges and recommendations for future satellite missions', Remote Sensing of Environment. Elsevier Inc., 160, pp. 15-30. doi: 10.1016/j.rse.2015.02.001.

Özerdem, M., Acar, E., \& Ekinci, R. (2017). Soil Moisture Estimation over Vegetated Agricultural Areas: Tigris Basin, Turkey from Radarsat-2 Data by Polarimetric Decomposition Models and a Generalized Regression Neural Network. Remote Sensing, 9(4), 395. https://doi.org/10.3390/rs9040395

Özerdem, M. S., \& Acar, E. (2017). Toprak nemi tahmini için Radarsat- 2 verisinden çoklu saçılma katsayılarının elde edilmesi, 00(412), 759-766.

Palmer, S. C. J. et al. (2015) 'Validation of Envisat MERIS algorithms for chlorophyll retrieval in a large, turbid and optically-complex shallow lake', Remote Sensing of Environment. Elsevier B.V., 157, pp. 158-169. doi: 10.1016/j.rse.2014.07.024.

Somvanshi.S et al. (2012) 'Integrated remote sensing and GIS approach for water quality analysis of Gomti river , Uttar Pradesh', International Journal of Environmental Sciences, 3(1), pp. 62-75. doi: 10.6088/ijes.2012030131008.

Sönmez, N. K. and Sarı, M. (2002) 'Uzaktan algılama temel prensipleri ve uygulama alanları', Derim, 19(2), pp. 16-30.

Strömbeck, N. and Pierson, D. C. (2001) 'The effects of variability in the inherent optical properties on estimations of chlorophyll a by remote sensing in Swedish freshwaters', Science of the Total Environment, 268(1-3), pp. 123-137. doi: 10.1016/S0048-9697(00)00681-1.

Toming, K. et al. (2016) 'First experiences in mapping lakewater quality parameters with sentinel-2 MSI imagery', Remote Sensing, 8(8), pp. 1-14. doi: 10.3390/rs8080640.

Watanabe, F. S. Y. et al. (2015) 'Estimation of chlorophyll-a concentration and the trophic state of the barra bonita hydroelectric reservoir using OLI/landsat-8 images', International Journal of Environmental Research and Public Health, 12(9), pp. 10391-10417. doi: 10.3390/ijerph120910391.

Zhou, Z. and Zhao, Y. (2011) 'Research on the water quality monitoring system for inland lakes based on remote sensing, Procedia Environmental Sciences, 10(PART B), pp. 1707-1711. doi: 10.1016/j.proenv.2011.09.268.

Zuccari Fernandes Braga, C., Setzer, A. W. and Drude de Lacerda, L. (1993) 'Water quality assessment with simultaneous Landsat-5 TM data at Guanabara Bay, Rio de Janeiro, Brazil', Remote Sensing of Environment. Elsevier, 45(1), pp. 95-106. doi: 10.1016/0034-4257(93)90085-C. 